\title{
Uremic tumoral calcinosis in the cervical spine: case report
}

\author{
Mostafa Fatehi, MD, MSc, ${ }^{2}$ Christopher S. Ahuja, MD, ${ }^{1,4}$ Shelly Wang, MD, BSc, ${ }^{1,3}$ and \\ Howard J. Ginsberg, MD, PhD, FRCSC $1,5,6$
}

\begin{abstract}
1Division of Neurosurgery, Department of Surgery, University of Toronto; ${ }^{4}$ Institute of Medical Science, University of Toronto; ${ }^{5}$ Department of Surgery and Institute of Biomaterials and Biomedical Engineering, University of Toronto; ${ }^{6}$ Keenan Research Centre, Li Ka Shing Knowledge Institute, St. Michael's Hospital, University of Toronto, Ontario; 'Division of Neurosurgery, Department of Surgery, University of British Columbia, Vancouver, British Columbia, Canada; and 'Department of Biostatistics and Epidemiology, Harvard School of Public Health, Boston, Massachusetts
\end{abstract}

\begin{abstract}
Tumoral calcinosis is an uncommon condition characterized by the calcification of periarticular soft tissue. In uremic patients the disease is secondary to metabolic disturbances in predisposed patients. The authors report the case of a 73-year-old woman who presented with a new painful cervical mass while undergoing continuous ambulatory peritoneal dialysis for long-standing end-stage renal disease (ESRD). A CT scan of the neck showed a lobulated, calcified mass in the left paraspinal soft tissue at $\mathrm{C} 2-3$. This mass affected the facet joint and also extended into the neural foramen but did not cause any neurological compromise. Due to the patient's significant medical comorbidities, resection was deferred and the patient was followed in the clinic. Subsequent repeat imaging has shown a significant decrease in the size of the mass. In the context of ESRD, a diagnosis of uremic tumoral calcinosis (UTC) was made. The authors conducted a search of the PubMed and EMBASE databases and identified 7 previously reported cases of UTC of the cervical spine. They present a summary of these cases and discuss the etiology, diagnosis, and management of the condition. Although the metabolic disturbances seen in patients undergoing dialysis can lead to tumoral calcinosis, most reported cases involve large joints such as the shoulder or the hip; however, the spine can also be affected and should be considered in the differential diagnosis of patients with uremia as it can mimic aggressive bone-forming neoplasms.
\end{abstract}

http://thejns.org/doi/abs/10.3171/2015.12.SPINE151085

KEY WORDS uremia; tumoral calcinosis; dialysis-related calcinosis; cervical spine; osteoblastic lesion

$\mathrm{C}$ ALCIFICATION of soft tissue (calcinosis) is a rare but serious complication affecting patients with chron(those undergoing dialysis. The precipitation of calcium salts occurs due to metabolic disturbances, including uremia, serum alkalosis, and an elevated calcium-phosphate product. ${ }^{12,19,20}$ The exact mechanism by which uremia leads to precipitation and calcium-phosphate derangements is not well understood. Calcinosis has been described in various cutaneous, subcutaneous, vascular, and visceral tissues. ${ }^{5,7,15,17}$ In patients with end-stage renal disease (ESRD), massive extraskeletal calcinosis can occur in periarticular soft tissues; this condition is termed uremic tumoral calcinosis (UTC).
UTC often presents as painful tumor-like masses around both large weight-bearing joints and smaller overused joints. ${ }^{3,4}$ The bony hard masses are most commonly extra-articular and rarely erode bone, however, they may extrude through the skin, creating an infection risk. While the etiology of UTC remains poorly understood, a consistent prerequisite is an elevated serum calcium-phosphate product $(\mathrm{Ca} \times \mathrm{P}){ }^{4,6,12}$

Currently, treating UTC in patients undergoing peritoneal dialysis remains challenging. Aggressive medical management alone does not always control tumoral calcinosis, and several studies have suggested adding intermittent hemodialysis as part of the treatment strategy to better 


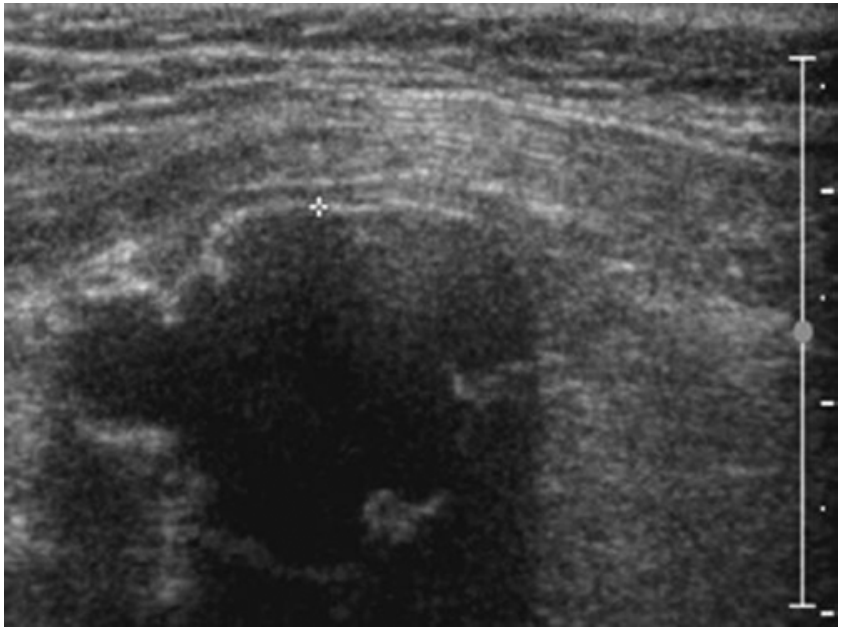

FIG. 1. Ultrasound image of the left neck obtained 1 month after presentation, showing a hypoechoic mass.

manage electrolyte abnormalities. ${ }^{4}$ Other medical interventions include dietary phosphorus restriction, oral phosphate chelation, utilizing low-calcium dialysate solutions, and calcimimetics. Surgical interventions including local mass resection and parathyroidectomy have also been suggested, but neither strategy is curative in all patients. To date, the only curative option remains kidney transplant.

Most cases involve the shoulder, hip, and metatarsophalangeal joints; spinal cases are, overall, quite rare. ${ }^{5} \mathrm{We}$ report on a 73-year-old woman who was undergoing peritoneal dialysis and presented to the neurosurgical service with a neoplastic-appearing UTC lesion of the cervical spine.

\section{Case Report}

This 73-year-old woman had hypertension, obstructive sleep apnea, hypothyroidism, and a renal transplant for ESRD secondary to polycystic kidney disease. One year prior to presentation her transplant failed and she had to resume dialysis. She subsequently had a myocardial infarction and developed congestive heart failure. She underwent intermittent hemodialysis for 4 months and then transitioned to peritoneal dialysis. Two months after beginning peritoneal dialysis (referred to as the presentation date hereafter), the patient presented with a growing painful mass in the left posterolateral aspect of her neck.

An ultrasound examination performed 1 month after presentation (Fig. 1) demonstrated a $2.1 \times 1.4 \times 2.6-\mathrm{cm}$ hypoechoic, avascular lesion located $1 \mathrm{~cm}$ deep to the skin within the posterior triangle of the neck. A follow-up CT scan performed 3 months after presentation (Fig. 2A and D) revealed an enlarged $2.9 \times 2.3 \times 2.2-\mathrm{cm}$ calcified, multilobular, and peripherally corticated mass in the paraspinal soft tissues adjacent to the left $\mathrm{C} 2-3$ facet joint. There was also extension into the left $\mathrm{C} 2-3$ intervertebral foramen. A bone scan (Fig. 3) showed increased uptake in the left paraspinal mass. The differential diagnosis included bone-forming neoplasms such as an osteochondroma, osteosarcoma, or chondrosarcoma. Blood tests at presentation showed various serum chemistry abnormalities, including elevated levels of urea $(23.0 \mathrm{mmol} / \mathrm{L}$, reference range $3.0-7.0 \mathrm{mmol} / \mathrm{L})$, phosphate $(2.67 \mathrm{mmol} / \mathrm{L}$, reference range $0.80-1.35 \mathrm{mmol} / \mathrm{L}$ ), and calcium-phosphate product $\left(6.35 \mathrm{mmol}^{2} / \mathrm{L}^{2}\right.$, reference range $1.68-3.51$ $\left.\mathrm{mmol}^{2} / \mathrm{L}^{2}\right)$.

Throughout, the patient denied radicular pain and was neurologically intact on detailed examination. Resection of this growing lesion, for diagnosis and potential tumor
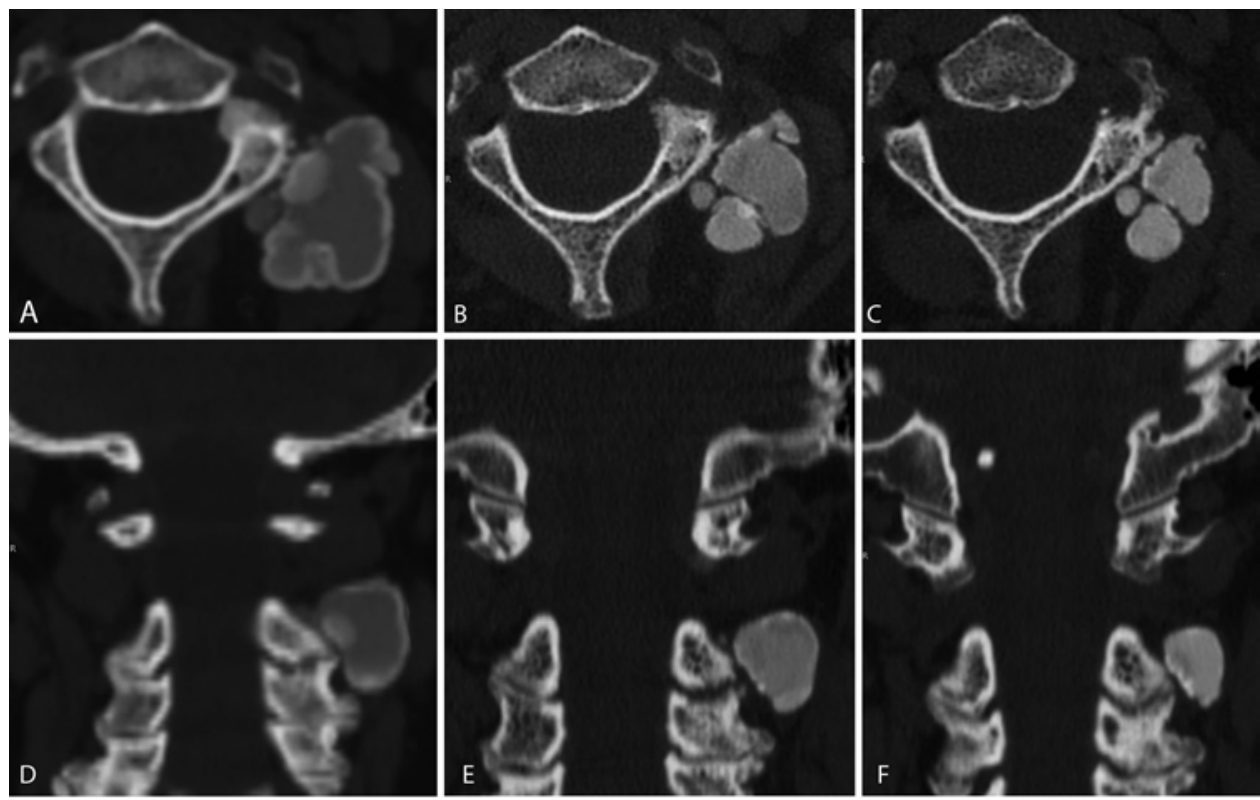

Presentation +3 Months

Presentation + 10 Months

Presentation + 17 Months

FIG. 2. Axial (A-C) and coronal (D-F) CT images of the cervical spine obtained at $3(A$ and $D), 10(B$ and $E)$, and 17 ( $C$ and $F)$ months after presentation, showing changes in the calcified paraspinal mass over time. 


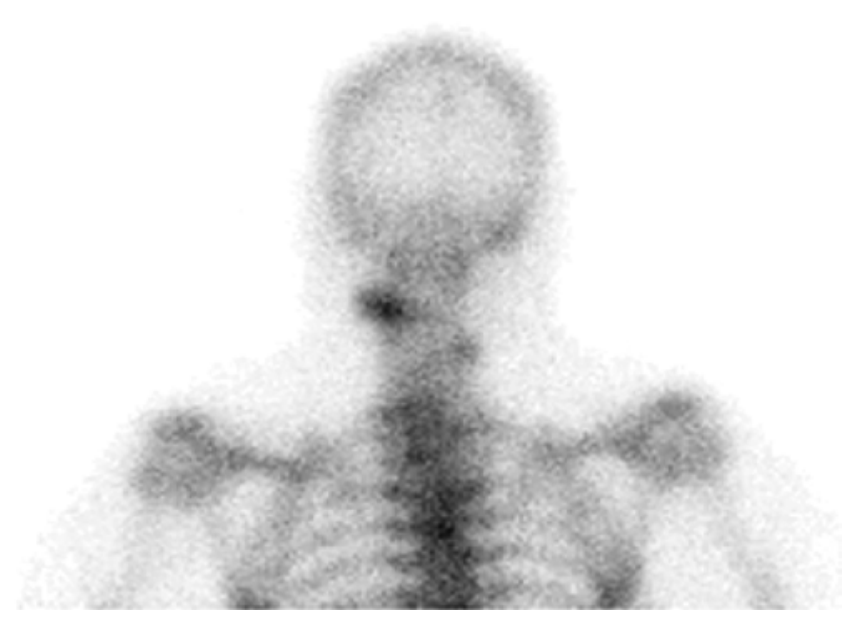

FIG. 3. Bone scan obtained 3 months after presentation, demonstrating increased uptake in a left neck mass.

control, was deferred until her medical status could be optimized, given her significant comorbidities. In the inter$\mathrm{im}$, hemodialysis was initiated, and a follow-up CT scan was performed 10 months after presentation (Fig. 2B and
E). This CT scan showed an unexpected decrease in the size of the lesion (to $2.4 \times 1.7 \times 1.8 \mathrm{~cm}$ ). Repeat blood tests confirmed ongoing uremia $(14.6 \mathrm{mmol} / \mathrm{L})$ but showed normalization of the calcium-phosphate product $\left(3.41 \mathrm{mmol}^{2} /\right.$ $\mathrm{L}^{2}$ ). Given this finding, the decision was made to continue monitoring the patient's clinical condition. Her neck pain decreased over time. At the time of this writing, the patient continues to receive hemodialysis, her neck pain has resolved, and she has had no other symptoms related to the lesion. A CT scan performed at 17 months after presentation demonstrated continued decrease in the size of the lesion (Fig. 2C and F).

\section{Literature Review}

A thorough search of the PubMed and EMBASE databases was completed on May 24, 2015, and citations from previous case reports were also reviewed. ${ }^{12,19}$ The search was limited to native and translated English-language articles. A PRISMA flow diagram (Fig. 4) outlines the systematic review.

Thirty-three potentially relevant references were identified on the basis of the MeSH keywords ("tumoral calcinosis" or "dialysis related calcinosis") and "cervical spine." An additional 2 cases were added from citation

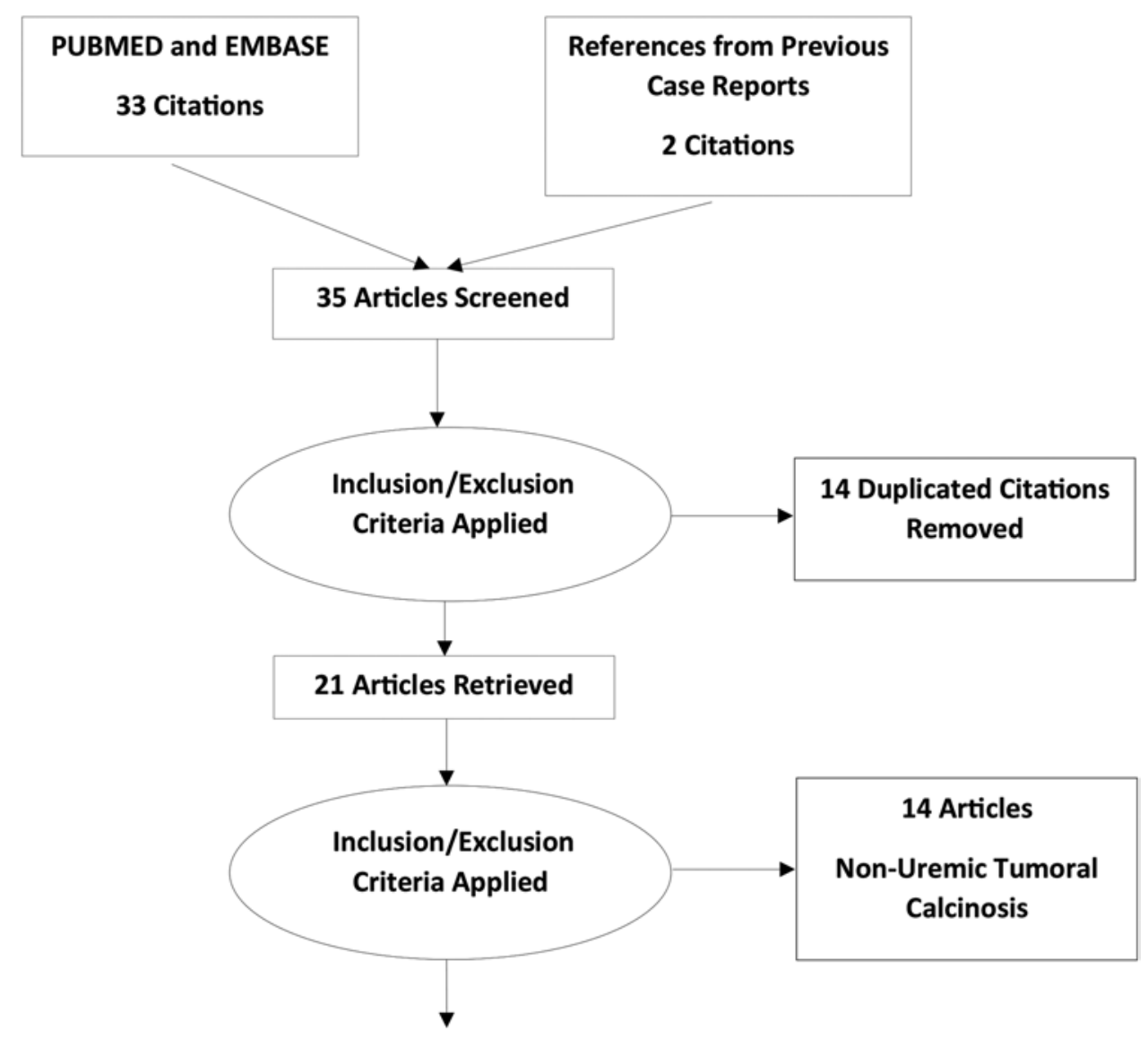

7 Articles Included

FIG. 4. PRISMA flow diagram outlining results of the literature review. Modified from Moher et al: Preferred Reporting Items for Systematic Reviews and Meta-Analyses: The PRISMA Statement. PLoS Med 6(7):e1000097, 2009. 
TABLE 1. Summary of reported cases of cervical UTC

\begin{tabular}{|c|c|c|c|c|c|}
\hline Authors \& Year & $\begin{array}{l}\text { Age (yrs) } \\
\text { Sex }\end{array}$ & Dialysis & Sx & Treatment & Follow-Up \\
\hline $\begin{array}{l}\text { Snitchler \& Silverman, } \\
2011\end{array}$ & $55, \mathrm{M}$ & $\mathrm{HD}$ & Cervical pain for $1 \mathrm{yr}$ & Not reported & Not reported \\
\hline Sunder et al., 2013 & $50, \mathrm{~F}$ & HD & Increasing neck mass for $1 \mathrm{yr}$ & Calcimimetic, subtotal PTX & $\begin{array}{l}\text { Relapse after } 2 \text { yrs, sig decrease in } \\
\text { size of lesion at } 4 \text { yrs }\end{array}$ \\
\hline Matsukado et al., 2001 & $54, \mathrm{~F}$ & HD & $\begin{array}{l}\text { Cervical pain, spastic gait, } \\
\text { upper-limb paresis }\end{array}$ & Local resection & Improvement of neurol Sx \\
\hline Carlson et al., 2007 & $39, \mathrm{~F}$ & $H D$ & $\begin{array}{l}\text { Progressive quadriparesis \& } \\
\text { right UE monoplegia }\end{array}$ & Local resection & $\begin{array}{l}\text { Initial neurol improvement, pt died } \\
\text { w/in } 6 \text { mos }\end{array}$ \\
\hline Jackson et al., 2007 & $29, \mathrm{~F}$ & $\mathrm{HD}$ & $\begin{array}{l}\text { Upper-back pain, paresthesias \& } \\
\text { paresis in left hand }\end{array}$ & $\begin{array}{l}\text { Local resection, total PTX, } \\
\text { renal transplant }\end{array}$ & $\begin{array}{l}\text { Resolution of neurol Sx \& calcinosis } \\
\text { at } 22 \text { mos }\end{array}$ \\
\hline $\begin{array}{l}\text { Remy-Leroux et al., } \\
2009\end{array}$ & $29, \mathrm{M}$ & $\mathrm{HD}$ & Increasing neck mass for 2 mos & PTX, renal transplant & $\begin{array}{l}\text { Complete resolution of tumoral cal- } \\
\text { cinosis w/o recurrence at } 6 \text { yrs }\end{array}$ \\
\hline Chang et al., 2013 & $44, \mathrm{~F}$ & PD & $\begin{array}{l}\text { Cervical pain, headache, \& } \\
\text { hypertension }\end{array}$ & $\begin{array}{l}\text { Local resection, phosphate } \\
\text { binder, calcimimetic }\end{array}$ & $\begin{array}{l}\text { Resolution of neurol Sx \& decreased } \\
\text { lesion sizes at } 1 \mathrm{yr}\end{array}$ \\
\hline
\end{tabular}

$\mathrm{HD}=$ hemodialysis; neurol = neurological; $\mathrm{PD}=$ peritoneal dialysis; $\mathrm{pt}=$ patient; $\mathrm{PTX}=$ parathyroidectomy; sig = significant; $\mathrm{Sx}=$ symptoms; UE = upper extremity.

lists. Fourteen duplicated results were removed and an additional 14 articles were excluded because they did not involve patients with uremia. Ultimately, 7 cases of UTC in the cervical spine were identified; these cases are summarized in Table 1.

\section{Discussion}

Uremic tumoral calcinosis (UTC) is a rare phenomenon affecting $0.5 \%-3 \%$ of patients with renal failure. ${ }^{4,19,20}$ In this disease, calcium-phosphate salts precipitate in the periarticular soft tissues surrounding weight-bearing or overused joints including spinal facet joints. A review of the English literature yielded 7 cases of UTC affecting the cervical spine; in 6 of these cases the patients were undergoing hemodialysis, and in 1 case the patient was undergoing peritoneal dialysis. In this limited sample, disproportionately more female patients were affected (5 female, 2 male).

The etiology of this disease is not fully understood, but systemic factors, genetic factors, and local conditions have been implicated. The most important systemic factor is hyperphosphatemia, which was reported in nearly all patients regardless of serum calcium levels. ${ }^{4,19,20}$ Local conditions that have been implicated in the stimulation of calcium salt deposition include trauma, hematomas, and de novo overproduction of calcifiable matrix protein. Other possible predisposing factors are genetic mutations in the FGF23 and GALNT3 genes, leading to a decrease in the level of functional fibroblast growth factors, which is associated with hyperphosphatemic tumoral calcinosis. ${ }^{1,8,15}$

In the spine, the differential diagnosis of a growing, calcified, paraspinal mass commonly includes sarcomas, primary osteochondral tumors, infection, and myositis ossificans. We stress the importance of including UTC in the differential diagnosis when managing a patient who may have an underlying metabolic disturbance. ${ }^{9}$

The cornerstone of medical therapy is correcting the underlying calcium and phosphate elevations. The 2005
Caring for Australasians with Renal Impairment (CARI) guidelines suggest achieving an albumin-corrected calcium-phosphate product of less than $4 \mathrm{mmol} / \mathrm{L}$ to minimize the risk of aberrant calcification (Level III evidence). ${ }^{7}$ To achieve this goal, many patients are treated with aggressive phosphate binders, calcimimetics, dietary phosphorus restriction, oral chelation, and increased length and frequency of hemodialysis treatments. ${ }^{19}$

Surgical approaches include both parathyroidectomy and local resection of masses. Two studies have reported performing parathyroidectomy in patients with severe hyperparathyroidism and hypercalcemia refractory to medical treatment. ${ }^{4,19,20}$ Resection is generally undertaken for lesions causing acute, progressive, or refractory neurological dysfunction. Surgery is also indicated where severe pain and functional limitation are attributable to the lesion. In a recent report of UTC causing atlantoaxial subluxation and limited range of motion due to pain, Chang et al. describe lesion resection and fusion resulting in satisfactory pain relief and functional improvement. ${ }^{3}$ In the subset of patients with tumoral calcinosis and continued metabolic disturbances, a recurrence rate of $33 \%$ has been reported..$^{10}$ Other studies have suggested that incomplete resection is associated with higher rates of recurrence. ${ }^{11,14,17}$

\section{Conclusions}

UTC may involve the cervical spine, causing pain and radiologically mimicking an osteoblastic neoplasm. Our patient might have undergone a surgical intervention had her significant medical comorbidities not led to initial conservative management. As her metabolic abnormalities resolved, the calcified mass significantly decreased in size. Consistent with previous reports, control of serum phosphate and calcium-phosphate product levels remains the cornerstone of preventing UTC. The unique presentation in this report highlights the importance of including UTC in the differential diagnosis of bone-forming lesions in patients with ESRD. 


\section{References}

1. Bergwitz C, Banerjee S, Abu-Zahra H, Kaji H, Miyauchi A, Sugimoto T, et al: Defective O-glycosylation due to a novel homozygous S129P mutation is associated with lack of fibroblast growth factor 23 secretion and tumoral calcinosis. J Clin Endocrinol Metab 94:4267-4274, 2009

2. Carlson AP, Yonas HM, Turner PT: Disorders of tumoral calcification of the spine: illustrative case study and review of the literature. J Spinal Disord Tech 20:97-103, 2007

3. Chang CC, Sung CC, Hsia CC, Lin SH: Uremic tumoral calcinosis causing atlantoaxial subluxation and spinal cord compression in a patient on continuous ambulatory peritoneal dialysis. Int Urol Nephrol 45:1511-1516, 2013

4. Chu HY, Chu P, Lin YF, Chou HK, Lin SH: Uremic tumoral calcinosis in patients on peritoneal dialysis: clinical, radiologic, and laboratory features. Perit Dial Int 31:430-439, 2011

5. Cofan F, García S, Combalia A, Campistol JM, Oppenheimer F, Ramón R: Uremic tumoral calcinosis in patients receiving longterm hemodialysis therapy. J Rheumatol 26:379-385, 1999

6. Hawley C: Calcium $\times$ phosphate product. Nephrology (Carlton) 11 (Suppl s1):S206-S208, 2006

7. Hawley C: Calcium $\times$ Phosphate Product. The CARI Guidelines-Caring for Australasians with Renal Impairment. Westmead, NSW, Australia: Kidney Health Australia, 2005

8. Ichikawa S, Baujat G, Seyahi A, Garoufali AG, Imel EA, Padgett LR, et al: Clinical variability of familial tumoral calcinosis caused by novel GALNT3 mutations. Am J Med Genet A 152A:896-903, 2010

9. Jackson W, Sethi A, Carp J, Talpos G, Vaidya R: Unusual spinal manifestation in secondary hyperparathyroidism: a case report. Spine (Phila Pa 1976) 32:E557-E560, 2007

10. King JJ, Brennan KB, Crawford EA, Fox EJ, Ogilvie CM: Surgical complications associated with extensive tumoral calcinosis. Am J Orthop 40:247-252, 2011

11. Kisembo H, Kiguli-Malwadde E, Kawooya MG: Tumoral calcinosis: report of nine cases. East Afr Med J 77:574-575, 2000

12. Lebl DR, Girardi FP: Isolated cervical spine facet joint tumoral calcinosis. Spine J 13:208-209, 2013

13. Matsukado K, Amano T, Itou O, Yuhi F, Nagata S: Tumoral calcinosis in the upper cervical spine causing progressive ra- diculomyelopathy-case report. Neurol Med Chir (Tokyo) 41:411-414, 2001

14. Noyez JF, Murphree SM, Chen K: Tumoral calcinosis, a clinical report of eleven cases. Acta Orthop Belg 59:249-254, 1993

15. Rafaelsen S, Johansson S, Ræder H, Bjerknes R: Long-term clinical outcome and phenotypic variability in hyperphosphatemic familial tumoral calcinosis and hyperphosphatemic hyperostosis syndrome caused by a novel GALNT3 mutation; case report and review of the literature. BMC Genet 15:98, 2014

16. Remy-Leroux V, Reguiaï Z, Labrousse AL, Zakine EM, Clavel P, Bernard P: [Tumoral calcinosis at an unusual site in a haemodialysis patient.] Ann Dermatol Venereol 136:350 354, 2009 (Fr)

17. Smack D, Norton SA, Fitzpatrick JE: Proposal for a pathogenesis-based classification of tumoral calcinosis. Int J Dermatol 35:265-271, 1996

18. Snitchler AN, Silverman JF: Cytologic diagnosis of tumoral calcinosis: a case report. Acta Cytol 55:478-480, 2011

19. Sunder S, Verma H, Venkataramanan K: Cervical tumoral calcinosis with secondary hyperparathyroidism in a chronic hemodialysis patient. Hemodial Int 17:458-462, 2013

20. Wong RH, Bhansali AP, Doppenberg EM: Cervical spine instability from tumoral calcinosis. Acta Neurochir (Wien) 155:1245-1246, 2013

\section{Disclosures}

The authors report no conflict of interest concerning the materials or methods used in this study or the findings specified in this paper.

\section{Author Contributions}

Conception and design: Ginsberg, Ahuja. Drafting the article: Fatehi. Critically revising the article: Ahuja, Wang. Reviewed submitted version of manuscript: all authors. Study supervision: Ginsberg.

\section{Correspondence}

Howard Ginsberg, St. Michael's Hospital, 3rd Fl. Bond Wing, 30 Bond St., Toronto, ON M5B 1W8, Canada.email: ginsbergh@ smh.ca. 